\title{
The Impact Of Human Interaction On The Development Of Virtual Teams
}

Silas T. Nunes, (E-mail: T2nunes@aol.com), Baker \& Hostetler LLP, Senior Consultant Gbolahan Solomon Osho, (E-mail: OshoS@uhd.edu), University of Houston

Chynette Nealy, (E-mail: NealyC@uhd,edu), University of Houston

\begin{abstract}
Virtual teams have revolutionized the ways in which organizations are able to improve business efficiency and productivity in the new era of globalization and information technology. Despite constant advancements in computer technology, virtual teams success continues to depend heavily on the ability of their members to communicate well and trust each other. This paper presents elements of successful virtual teams and accentuates the need for improved human interaction skills.
\end{abstract}

\section{INTRODUCTION}

$\mathscr{I}$

$\mathrm{n}$ the present interconnected global economy, competitive demands are forcing many organizations to reassess their business strategies in order to be more productive and efficient in their daily operations. One of the most revolutionary approaches to achieve such outcomes has been the development of virtual teams in organizations. Virtual teams are alliances formed to exploit complementary skills in the pursuit of common strategic objectives, operating remotely from each other and from managers, and relying heavily on communication technology to accomplish organizational tasks (Cascio, 2000). The main purpose of virtual teams is to increase collaborative work across organizational, spatial, and political borders (Van der Smagt, 2000). However, such collaboration can only be achieved if the underlying elements of human interaction are sufficiently better than those of traditional environments.

Several researchers such as Stough, Eom and Buckenmyer (2000) recognized that companies must find ways to bring human resources together quickly and efficiently to take advantage of dispersed resources, rather than having to physically assemble them in a single location. Since companies often lack expertise or resources in all areas, the virtual organization (and virtual teams) is formed. Virtual teamwork has become not only a reality, but a genuine need for both big and small organizations. As Jarvenpaa and Leidner (1999) describe, virtual teams provide the essential elements necessary to meet ever-changing task requirements in highly turbulent and dynamic global business environments.

Virtual teams allow business organizations to maximize and effectively utilize manpower separated by geographical barriers, different time zones, and organizational boundaries. Individual talents and abilities are no longer constrained to organizations' branches, divisions, or offices, but can be mutually employed for the benefit of the entire organization. Through the use of computer-mediated communication technologies, virtual teams can collaborate instantaneously and continuously by making the most of hidden manpower dispersed throughout an organization. As the cost of modern networking technologies falls and the reality of globalization transforms business practices, virtual teams are becoming increasingly more appealing to organizations. Consequently, virtual teams have begun to emerge as the best alternative to meet the challenges of a new work context surrounded by sophisticated information and communication technologies (Kayworth and Leidner, 2002).

While the prospective for the development of virtual teams are tremendously favorable through the application of modern technology, the successful maintenance of virtual teams hinges on improved human relations and interaction. Kezborm (2000) makes this point clear by asserting that organizations cannot rely on technology 
alone to create a sense of commitment and teamwork. Sirkka and Dorothy (1999) also point out that although virtual teams promise the flexibility, responsiveness, lower costs, and improved resource utilization necessary to meet the challenges of the dynamic global business environment, they are also prone to problems, a "dark side" of virtual teams characterized by low individual commitment, role overload, role ambiguity, absenteeism, and social loafing.

Hence, the purpose of this paper is to evaluate whether virtual teams can function effectively without the face-to-face interaction, cohesiveness and collaboration observed in traditional collocated teams. Specifically, this paper analyzes how communication and trust affect the development of successful virtual teams.

\section{BENEFITS OF VIRTUAL TEAMS}

Furst, Blackburn, and Rosen (1999) found that some of the benefits of virtual teams include the generation of a greater number of ideas and information, the offset of personal biases, the discovery of expert knowledge within organizations, and the ability to share "best practice" information nearly instantaneously. The effective use of information technology tools to accomplish organizational tasks through computer-mediated systems is essential in the development of successful virtual teams. Table 1 describes some of the modern technologies available to support virtual teams.

The technology resources described in Table 1 represent the current tools available to support virtual teams. Although extremely useful and advanced, these tools considered by themselves, do not avail much. The success of virtual teams requires the adoption of a holistic approach that encompasses elements such as, improved common understanding, open relationships, trust, and effective communication among virtual team members (Kezbom, 2000).

Bal \& Foster (2000) concluded that no one element can do the job. It is the integrated development of teams, technologies, and organizational structures that creates high performance.

Extending this conclusion, Bal \& Foster (2000) describe the results of implementing virtual teams:

- $\quad$ Teams can be organized, irrespective of their location;

- $\quad$ Firms can engage outside consultants more often if they don't have to incur expenses for travel and lodging;

- $\quad$ Employees can have more flexible schedules;

- $\quad$ Team members can be assigned to different projects;

- $\quad$ Employees can be assigned to multiple, concurrent teams;

- Information is readily available online to facilitate swift responses to the demands of global markets;

- $\quad$ Clients benefit from the prompt response to their needs.

\section{POTENTIAL HUMAN INTERACTION PROBLEMS IN VIRTUAL TEAMS}

Although the vast benefits of virtual teams justify their implementation in business organizations, there is always the potential for problems when there is a reduction in the amount of formal or informal contact within the ranks of the workforce. Stough, Eom, \& Buckenmyer, (2000) asserted that the loss of personal contact between managers and workers, such as the day-to-day discussions, water-cooler philosophizing, and networking affects productivity because of an inability of people to handle the freedom of the virtual environment. Additionally, many people do not realize that the virtual environment is substantially different from traditional environments, especially in the area of communication. For example, nonverbal cues such as body language, gestures, voice tone, inflection, and pitch are no longer part of the communication process (Kezbom, 2000). As a result, the lack of nonverbal communication, which can account for as much as 60 percent of the message conveyed by an individual, may lead to misunderstandings, confusion, and frustration, which in turn affects the ability of virtual team members to work effectively. 
A primary example is dissatisfaction with the reward and recognition systems for outstanding performance (Stough, Eom, \& Buckenmyer, 2000). It is possible that the reduced interaction between managers and subordinates may cause a manager to be unaware of special efforts, dedication, and exceptional work performed by employees. Managers must be aware of the fact that the lack of human context can aggravate minor issues and can block the development of effective virtual teams. Employees need to feel certain that the performance evaluation process will be fair and accurate despite the lack of personal interaction between them and their managers.

The same basic principles of management apply to virtual teams. However, virtual team managers must realize that virtual workplaces, instead of needing fewer managers, require better supervisory skills among existing managers (Cascio, 2000). Some of these skills include open, prompt, and regular communication, coaching, and positive attitudes. Virtual team managers' characteristics include:

- $\quad$ An open, positive attitude that focuses on solutions to issues rather than on reasons to discontinue virtualwork arrangements;

- A results-oriented management style. Those who need structure and control are unlikely to be effective managers in virtual work environments;

- $\quad$ Effective communication skills, both formal and informal, with employees working remotely and at the primary business location;

- $\quad$ An ability to delegate effectively, and to follow up to ensure that work is accomplished (Cascio, 2000).

Effective management of virtual teams requires that managers adopt a management style that focuses on managing projects, rather than managing time. Kayworth \& Leidner (2002) finding from a quantitative data analysis of effective team leadership behavior support this results-based style. Mentoring capabilities of the team leader is key. Emerging from this interaction is effective communication that establishes role clarity among team members.

\section{RESULTS AND FINDINGS}

The purpose of this study was to evaluate whether virtual teams can function effectively without face-toface interaction, cohesiveness and collaboration observed in traditional collocated teams. An open-end question survey developed by Kayworth \& Leidner ( 2002 was used in the analysis of how communication and trust affect the development of successful virtual teams. The data collection process of the survey measured participants' perceptions on a scale of 1 to 5 along several variables: leadership effectiveness, leadership roles, perceived role clarity, communication effectiveness, communication satisfaction, and extent of communication technology used. Table 2 presents the variables, means, and standard deviation resulting from the data analysis in this survey.

Kayworth \& Leidner (2002) also reported that in their quantitative data analysis, regression was run using leadership effectiveness as the dependent variable, and the various roles and technology variety as independent variables. The regression is described as being significant $(F=7.46, p>0.000)$, however, the only role to significantly predict leadership effectiveness is that of Mentor $(t=3.547, p>0.001)$.

While the results of this study clearly focus on the capability and characteristics of successful virtual team leaders, organizations must also pay close attention to the selection process of virtual team members. It is important that managers select individuals who will be able to handle responsibilities inherent with the virtual environment. Personal traits and characteristics such as, "responsibility, dependability, independence, and self-sufficiency, while desirable even in face-to-face settings, are crucial to the viability of virtual teamwork" (Jarvenpaa \& Leidner, 1999). As a result, the successful implementation of virtual teams depends largely on managers' ability to identify individuals who will be able to interact effectively with other team members.

Another critical element necessary in effective management of virtual teams is a manager's ability to handle conflict. According to Jarvenpaa \& Leidner (1999), one strategy is to address perceived discontent as early as noticed because emotions left unchecked in the virtual environment might erupt into sequences of negative comments that will be difficult to resolve asynchronously. In this context, it is even more critical to possess the ability to interact effectively with the involved parties, so that communication messages are clearly articulated and 
understood. In other cases, the virtual environment may not be conducive to handle specific situations and it may become necessary to conduct face-to-face meetings to ensure proper communication.

It is also vital to the effective management of virtual teams that during the initial stages of virtual teams, managers define roles and responsibilities with the highest degree of clarity as possible. The clarity of these elements is paramount to the proper interaction among virtual team members, as a lack of such may lead to confusion, frustration, and disincentive. In addition, it is imperative that team members have a sense of complementary objectives and partaking in the overall aim of the team in order to avoid desultory participation (Jarvenpaa \& Leidner, 1999).

Kayworth \& Leidner (2002) summarized the critical behaviors for effective virtual team leadership using three different perspectives: trait, behavioral and contingency theories (see Table 3). Although not very different from the critical behaviors necessary in co-located teams, the distinction here is based on the weight that these behaviors have on the development of successful virtual teams. In short, virtual teams require much better interpersonal skills.

In contrast, ineffective leaders are generally perceived to lack empathy and to be detached from the management process. Furthermore, the lack of a mentoring approach prevents them from building healthy social climates where team members can interact with each other. (Kayworth \& Leidner, 2002).

\section{KEYS TO SUCCESSFUL VIRTUAL TEAMS}

Literature related to factors that determine success in virtual teams reveals a common thread in almost all of their discussions: trust is a fundamental element in virtual teams. Without trust, the geographical and organizational distances of virtual teams become psychological distances (Jarvenpaa \& Leidner, 1999). One pessimist in the group has the potential to undermine trust in the entire virtual team, and lack of trust affects overall group productivity (Cascio, 2000). Studies have demonstrated that in the absence of trust, team members reduce their own efforts and withhold cooperation with others (Furst, Blackburn, \& Rosen, 1999). The building of successful virtual teams must rest on a foundation where individual team members actively build trust in each other.

In their book on virtual teams, Lipnack \& Stamps (1997) assert the importance of trust in virtual teams:

Through interactions near and far, people develop trusting relationships, the invisible bonds (and baffles) of life... As important as positive relationships and high trust are in all teams, they are even more important in virtual ones. The lack of daily face-to-face time, offering opportunities to quickly clear things up, can heighten misunderstandings. For many distributed teams, trust has to substitute for hierarchical and bureaucratic controls.

Trust is indispensable in virtual teams, but it is also the most difficult component to learn and apply, especially if first impressions have already been formed. Nonetheless, it can be achieved, learned, and restored.

\section{RECOMMENDATIONS FOR IMPROVING HUMAN INTERACTION IN VIRTUAL TEAMS}

Stough, Eom \& Buckenmeyer (2000) suggest that in order to increase the effectiveness of virtual teams there must first exist a management structure that supports the virtual team concept. Management should play a strong sponsorship and a facilitative role that encourages interaction among team members. These interactions must recognize achievements of all magnitudes within the virtual environment. This can be particularly difficult to achieve given geographical separation may cause efforts to go unnoticed, and therefore unrecognized. Training concerning effective virtual teaming must be conducted throughout the internal organization to make employees aware of virtual teams' issues and how to increase efficiency and productivity by maximizing interpersonal skills.

Another major element needed to improve the human interaction in virtual teams, according to Stough, Eom \& Buckenmeyer (2000), is the essential element of trust. Although the development of trust among individuals is not an easy task, it may help to plan periodic face-to-face socialization meetings designed to develop personal contact and to celebrate virtual team accomplishments. Guidelines with a set of directions including mission, vision, 
and objectives, along with proper criteria for measuring virtual teaming effectiveness, must be implemented and consistently used.

\section{CONCLUSIONS}

Virtual teams have enabled organizations to improve efficiency and productivity by leveraging the unique abilities of individuals that are separated by time, space, and even organizational boundaries. However, the personal qualifications needed in virtual teams' members is significantly different than those of traditional settings. Two key elements of human relations are paramount to achieve success in the implementation of virtual teams: communication and trust. Even with the most modern computer-mediated communication technology available, effective teamwork will depend on each virtual team member's abilities to communicate well and to trust one another. As Kezbom (2000) asserted, effective teamwork is difficult in the best of times and conditions, so virtual teams members must work extra hard to develop interpersonal skills that will enable them to be effective in the environment in which they work.

The successful development of virtual teams requires a high degree of teamwork and a remarkable ability to interact with other people. Special interpersonal skills are required in order to compensate for the subtleties and context that are so easily lost in any virtual structure. Technology alone cannot guarantee the success of virtual teams, but applied in conjunction with superior interpersonal skills, it can become a factor that differentiates business organizations in the $21^{\text {st }}$ century.

\section{Table 1. Technologies Available to Support Virtual Teams}

\begin{tabular}{|l|l|}
\hline \multicolumn{1}{|c|}{ Technology } & \multicolumn{1}{c|}{ Description } \\
\hline Management Information Systems (MIS) & $\begin{array}{l}\text { Computer system that stores and integrates information from throughout the } \\
\text { organization for retrieval and use in decision making. }\end{array}$ \\
\hline Executive Information Systems (EIS) & $\begin{array}{l}\text { Computer systems that allow organizations to search many external sources for } \\
\text { information on specified topics relevant to company operations and strategy. }\end{array}$ \\
\hline Group Decision Support System (GDSS) & $\begin{array}{l}\text { Computer and communication technologies configured to maintain data } \\
\text { sources, enhance information capacity, and provide decision-making structures } \\
\text { for individuals and group. }\end{array}$ \\
\hline Intelligent Agents & $\begin{array}{l}\text { Software that sifts and sorts information, establishing links and redirecting to } \\
\text { appropriate parties. }\end{array}$ \\
\hline Expert Systems & $\begin{array}{l}\text { Computer programs that provide technical knowledge on various } \\
\text { organizational task and processes in a human-like form. }\end{array}$ \\
\hline
\end{tabular}

Source: Ball \& Foster (2000)

Table 2. Descriptive Statistics of Leadership Behavior

\begin{tabular}{|l|c|c|}
\hline \multicolumn{1}{|c|}{ Variable } & Mean & Standard Deviation \\
\hline Leadership effectiveness & 3.46 & 0.74 \\
\hline Communication effectiveness & 3.16 & 0.74 \\
\hline Communication satisfaction & 3.26 & 0.86 \\
\hline Role clarity & 3.47 & 0.78 \\
\hline Leader roles: & & 0.86 \\
\hline Innovator & 2.68 & 1.08 \\
\hline Broker & 3.40 & 1.04 \\
\hline Producer & 3.25 & 1.06 \\
\hline Director & 3.01 & 1.07 \\
\hline Coordinator & 3.04 & 1.03 \\
\hline Monitor & 3.09 & 1.06 \\
\hline Facilitator & 2.97 & 0.82 \\
\hline Mentor & 3.41 & \\
\hline
\end{tabular}

Source: Kayworth \& Leidner (2002) 
Table 3. Critical Behaviors for Effective Virtual Team Leadership

\begin{tabular}{|l|c|c|}
\hline \multicolumn{1}{|c|}{ Trait Theory } & Behavioral Theory & Contingency Theory \\
\hline Administrator & Provide meaningful goals & Create a supportive environment \\
\hline Coach & Build confidence and commitment & Develop trust \\
\hline Advisor & Strengthen mix and level of skill & Create and communicate a clear vision \\
\hline & Manage outside relationships & Act as a role model \\
\hline
\end{tabular}

Source: Kayworth \& Leidner (2002)

\section{References}

1. Bal, J. and Foster, P. (2000). "Managing the Virtual Team and Controlling Effectiveness." International Journal of Production Research, 38, 40-54.

2. $\quad$ Cascio, W. F. (2000). "Managing a Virtual Workplace.” Academy of Management Executive, 14, 81-91.

3. $\quad$ Communication In Virtual Teams (Strategic Communication Management, 2001).

4. Furst, S., Blackburn, R., and Rosen, B. (1999). "Virtual Team Effectiveness: A Proposed Research Agenda." Information Systems Journal, 9, 249-270.

5. Jackson, P. J. (1999). "Organizational Change and Virtual Teams: Strategic and Operational Integration." Information Systems Journal, 9, 313-333.

6. Jarvenpaa, S. L. and Leidner, D. E. (1999). "Communication and Trust in Global Virtual Teams." Organization Science: A Journal of the Institute of Management Sciences, 10, 791-816.

7. Kayworth, T. R. and Leidner, D. E. (2002). "Leadership Effectiveness in Global Virtual Teams.” Journal of Management Information Systems, 18, 7-41.

8. Kelley, E. (2001). "Keys to Effective Virtual Global Teams." Academy of Management Executive, 15, 132134.

9. $\quad$ Kezsbom, D. S. (2000). "Creating Teamwork in Virtual Teams." Cost Engineering, 42, 33-36.

10. Lipnack, J. and Stamps, J. (1997) "Virtual Teams." In: Reaching Across Space, Time, and Organizations with Technology, John Wiley \& Sons, New York.

11. Stough, S., Eom, S., \& Buckenmyer, J. (2000). "Virtual Teaming: A Strategy For Moving Your Organization Into The New Millennium.” Industrial Management \& Data Systems, 100, 370-379.

12. Van der Smagt, T. (2000). "Enhancing Virtual Teams: Social Relations V. Communication Technology." Industrial Management \& Data Systems, 100, 148-160. 